\title{
Comparison of Standard Light Water Reactor Cross-Section Libraries using the United States Nuclear Regulatory Commission Boiling Water Reactor Benchmark Problem
}

\author{
Joel A. Kulesza a and F. Arzu Alpan \\ Westinghouse Electric Company LLC 1000 Westinghouse Drive, Cranberry Township, PA 16066, USA
}

\begin{abstract}
This paper describes a comparison of contemporary and historical light water reactor shielding and pressure vessel dosimetry cross-section libraries for a boiling water reactor calculational benchmark problem. The calculational benchmark problem was developed at Brookhaven National Laboratory by the request of the U. S. Nuclear Regulatory Commission. The benchmark problem was originally evaluated by Brookhaven National Laboratory using the Oak Ridge National Laboratory discrete ordinates code DORT and the BUGLE-93 cross-section library. In this paper, the Westinghouse RAPTORM3G three-dimensional discrete ordinates code was used. A variety of cross-section libraries were used with RAPTOR-M3G including the BUGLE93, BUGLE-96, and BUGLE-B7 cross-section libraries developed at Oak Ridge National Laboratory and ALPAN-VII.0 developed at Westinghouse. In comparing the calculated fast reaction rates using the four aforementioned cross-section libraries in the pressure vessel capsule, for six dosimetry reaction rates, a maximum relative difference of $8 \%$ was observed. As such, it is concluded that the results calculated by RAPTOR-M3G are consistent with the benchmark and further that the different vintage BUGLE cross-section libraries investigated are largely self-consistent.
\end{abstract}

\section{Introduction}

This paper documents radiation transport calculations using the Westinghouse-developed RApid Parallel Transport Of Radiation - Multiple 3D Geometries (RAPTOR-M3G) code, version 2.0 [1], with Oak Ridge National Laboratory-developed Broad User Group Library ENDF/B-93 (BUGLE93) [2], BUGLE-96 [3], and BUGLE-B7 [4] cross-section data and A Library for Photons And Neutrons with ENDF/B-VII.0 (ALPAN-VII.0) [5] for the U.S. Nuclear Regulatory Commission (NRC) boiling water reactor (BWR) pressure vessel fluence calculational benchmark problem [6].

The RAPTOR-M3G code is a three-dimensional (3D) radiation transport code that solves the linear Boltzmann transport equation in $\mathrm{X}-\mathrm{Y}-\mathrm{Z}$ or $\mathrm{R}-\Theta-\mathrm{Z}$ geometries using the method of discrete ordinates $\left(S_{N}\right.$ method) via parallel processing. The parallel processing capability of RAPTOR-M3G was implemented using Message Passing Interface (MPI) libraries. The BUGLE-93 and BUGLE96 libraries were developed at Oak Ridge National Laboratory (ORNL) and contain a coupled 47neutron, 20-gamma-ray group cross-section library for light water reactor shielding and pressure vessel dosimetry applications derived from ENDF/B-VI.2 and ENDF/BVI.3 [7], respectively. The BUGLE-B7 library, the latest of the BUGLE libraries, has the same group structure of BUGLE-93 and BUGLE-96

\footnotetext{
${ }^{a}$ Corresponding author: jkulesza@umich.edu
} 


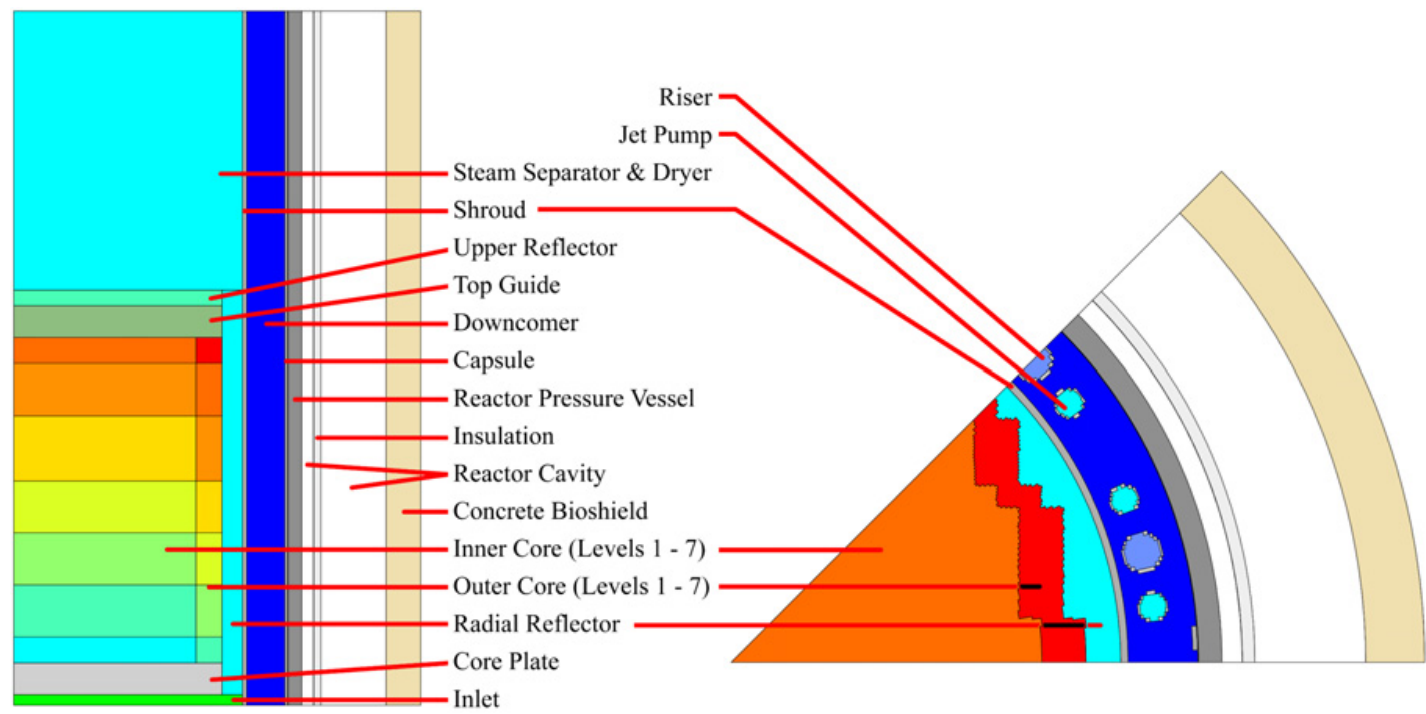

Figure 1. Elevation (left) and Plan (right) Views of the BWR Geometry.

and uses ENDF/B-VII.0. ALPAN-VII.0 was developed at Westinghouse for pressurized water reactor (PWR) internals and pressure vessel dosimetry applications, based on ENDF/B-VII.0 [8] and using the contributon and point-wise cross section driven methodology [9]. ALPAN-VII.0 contains crosssection sets with coupled 461-neutron, 42-gamma-ray-group and coupled 44-neutron, 20-gamma-ray group structures. The 42- and 20-gamma-ray group structures were taken from VITAMIN-B6 [3] and BUGLE-96, respectively. Therefore, only the neutron group structure of ALPAN-VII.0 was developed at Westinghouse. In this project, only ALPAN-VII.0 in broad-group structure (coupled 44-neutron, 20-gamma-ray-group) was used.

The U. S. NRC BWR vessel fluence benchmark problem is for a typical 800 fuel bundle BWR core including the radial reflector, shroud, jet pumps, riser columns, and a vessel having an inner radius of $321.31 \mathrm{~cm}$. The thermal power is $3833 \mathrm{MWt}$. The fuel active length is $381.0 \mathrm{~cm}$.

Reference 6 provides results of the U. S. NRC benchmark problems calculated using the ORNL two-dimensional (2D) discrete ordinates code DORT version 2.8.14 and the BUGLE-93 cross-section library. Monte Carlo calculations using MCNP4B were also performed to validate the 2D/1D synthesis results derived from DORT.

\section{Geometry Modeling}

The BOT3P code was used for modeling a single R- $\Theta-Z$ octant of the BWR based on the geometry specifications provided in Reference 6. The plan and elevation views of the 3D reactor model created by BOT3P are shown in Fig. 1 along with labels of key components. The model extends almost $500 \mathrm{~cm}$ radially and over $800 \mathrm{~cm}$ axially. The model includes $\sim 9 \mathrm{M}$ mesh (322 radially, 87 azimuthally, and 323 axially). Reflective and vacuum boundaries were used to treat particle leakage.

\section{Source Distribution}

A Westinghouse-developed source generation code, SORCERY, was used to produce a fixed distributed $\mathrm{R}-\Theta-\mathrm{Z}$ source distribution throughout the core region of the octant model. The initial fuel bundle enrichments were not provided in Reference 6. However an approximate enrichment of $3.1 \%$ was used for all assemblies. This approximation was based on examining the isotopic inventory of the 
Table 1. Flux Spectrum Reporting Positions.

\begin{tabular}{|c|c|c|c|}
\hline Region & Radius (cm) & Azimuth (degrees) & Elevation (cm) \\
\hline Downcomer & 278.100 & 23.500 & 306.605 \\
\hline Pressure Vessel Capsule & 319.195 & 3.000 & 306.605 \\
\hline Cavity & 398.700 & 44.975 & 282.602 \\
\hline
\end{tabular}

various inner and outer core materials and applying engineering judgment based on the quantities given and typical enrichments found in equilibrium BWR core loadings. The approximation was further validated by comparing fission fractions, by nuclide, at various exposures using the method described in Reference 10.

The fuel bundle radial relative powers were obtained from Reference 6 . The bundle power distributions were further defined on an $8 \times 8$ fuel bundle pin-wise power distribution. All intra-fuel bundle power distributions were modeled within the level of detail available (i.e., quarter-bundle powers were given for interior bundles, then the pins were lumped into $2 \times 2$ groups, and finally pin-by-pin powers were explicitly defined on the outermost peripheral bundles). The bundles were modeled with an overall pitch of $15.24 \mathrm{~cm}$ and an individual pin pitch of $1.61544 \mathrm{~cm}$.

The smeared or explicit pin-by-pin relative power distributions of the bundles input to the SORCERY code were obtained from data on a CD distributed with Reference 6. The bundle-wise relative powers were normalized such that one-eighth of the total core power equaled 1.0. The pin-by-pin distributions for each bundle were re-normalized to average 1.0 over all pin locations. In addition, the axial power distribution taken from Reference 6 was also given as input to the Westinghouse-developed source generation code.

Finally, the average core power density (calculated as $54.14 \mathrm{~W} / \mathrm{cm}^{3}$ ) was provided to SORCERY to generate a fixed distributed source throughout all of the fuel mesh, considering the inter-bundle gaps, for all neutron energy groups.

\section{Material Cross Sections}

Atom densities of each component in the BWR materials are directly given in Reference 6. The ICE code (from the SCALE6 suite of analysis tools) was used to generate mixture cross sections for BUGLE-93, BUGLE-96, and BUGLE-B7 in the broad-group structure described previously. Mixture cross sections included downscattering cross sections only, with an upscattering removal treatment in thermal energies.

\section{Dosimetry Cross Sections}

For the transport calculations, 47-neutron-group dosimetry cross sections provided in Reference 6 for ${ }^{46} \mathrm{Ti}(\mathrm{n}, \mathrm{p}),{ }^{54} \mathrm{Fe}(\mathrm{n}, \mathrm{p}),{ }^{58} \mathrm{Ni}(\mathrm{n}, \mathrm{p}),{ }^{63} \mathrm{Cu}(\mathrm{n}, \alpha),{ }^{237} \mathrm{~Np}(\mathrm{n}, \mathrm{f})$, and ${ }^{238} \mathrm{U}(\mathrm{n}, \mathrm{f})$ were used without modification to generate dosimetry responses for comparison purposes. For the ALPAN-VII.0 broad-group transport calculations, 44-neutron-group dosimetry cross sections were calculated by processing ENDF/B-VI.2 data with NJOY in 461-neutron groups (the fine-group ALPAN-VII.0 group structure) and using AMPX modules for further processing. For the 461-neutron-group to 44-neutron group collapsing, a $1 / 4 \mathrm{~T}$ PWR pressure vessel flux spectrum was used (due to the lack of an appropriate BWR spectrum), which was obtained from a 3-loop PWR model. The dosimetry responses of the reactions of interest used herein are provided in Table 1 of Reference 10.

\section{Transport Calculations}

The three-dimensional RAPTOR-M3G code was used to perform transport calculations with an $\mathrm{S}_{16}$ quadrature and $\mathrm{P}_{3}$ scattering cross sections with all cross-section libraries for the calculational benchmark defined in Reference 6. Often, an $\mathrm{S}_{8}$ quadrature is used in conjunction with a $\mathrm{P}_{3}$ scattering 


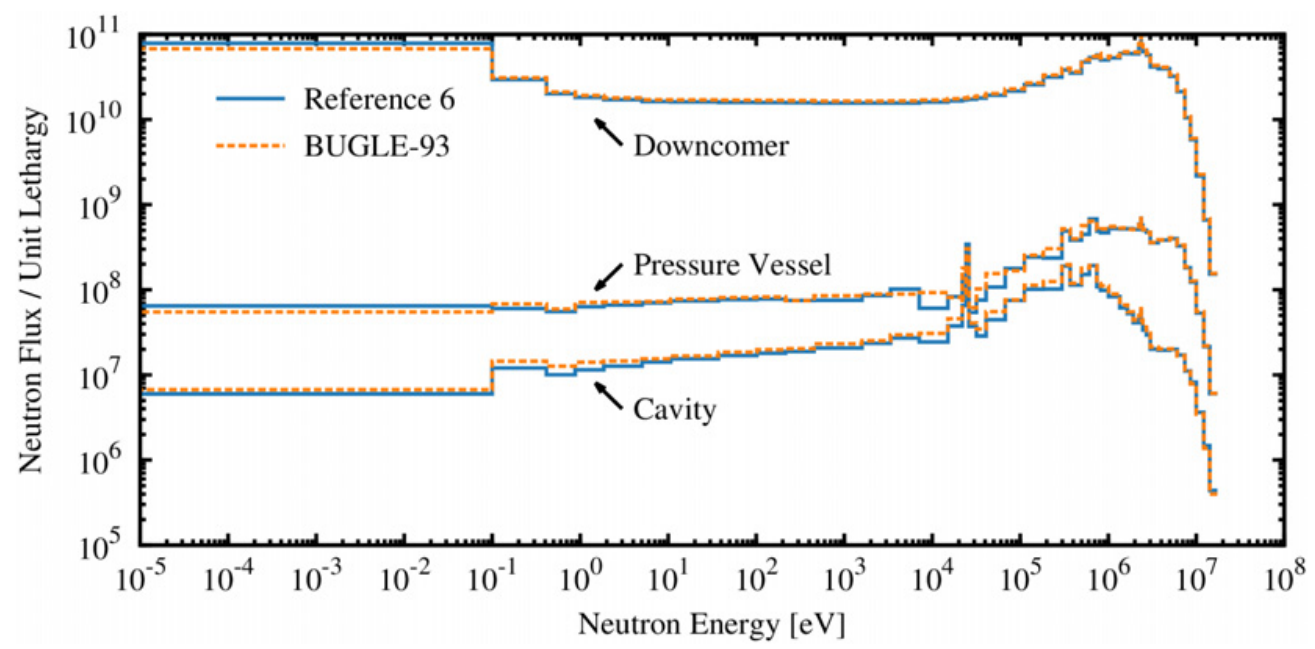

Figure 2. Comparison of BUGLE-93 Results Computed Herein to Reference 6.

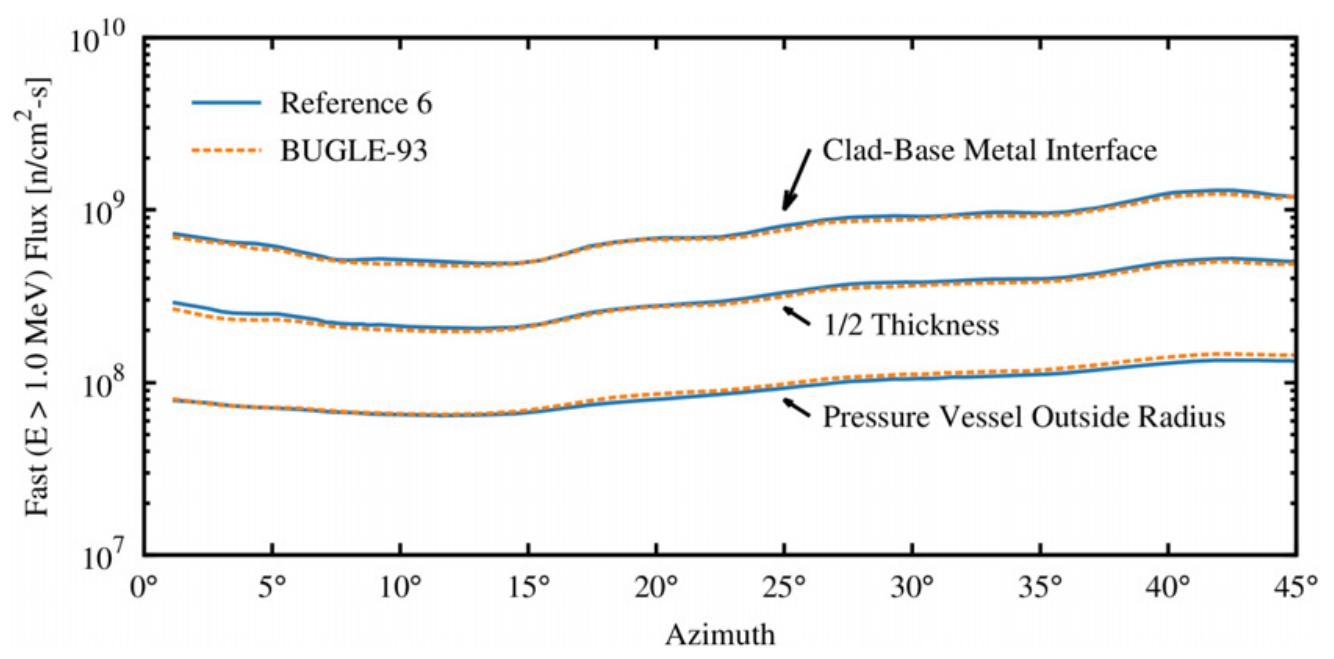

Figure 3. Comparison of Azimuthal Fast $(\mathrm{E}>1.0 \mathrm{MeV})$ Flux Traverses at Various Pressure Vessel Radii.

expansion. However, $\mathrm{S}_{16}$ was used in this case to provide better angular resolution in the large, lowscattering, regions such as the steam separator and dryer and the reactor cavity. A flux convergence criterion of $10^{-2}$ was used for inner iterations. While a tighter convergence of $10^{-3}$ is preferable, limited computing resources necessitated a relaxation. However, it is known from other endeavors that $10^{-2}$ still affords adequate convergence for the type of applications described herein. Results of the RAPTOR-M3G calculations performed herein were compared with the DORT 2D/1D synthesis results (which combined separate $1 \mathrm{D} R$ and $2 \mathrm{D} \mathrm{R}-\Theta$ and $\mathrm{R}-\mathrm{Z}$ geometries) provided by Reference 6 . The calculations performed in Reference 6 used an $\mathrm{S}_{8}$ quadrature and $\mathrm{P}_{3}$ scattering cross sections from the BUGLE-93 cross-section library and used a flux convergence criterion of $10^{-3}$ for inner iterations. As noted previously, the flux synthesis results were validated within Reference 6 using a fully-3D multigroup MCNP4B model.

In order to first validate the calculational model developed herein, the BUGLE-93 results were compared with Reference 6 as shown in Fig. 2. The three locations where the comparisons took place 


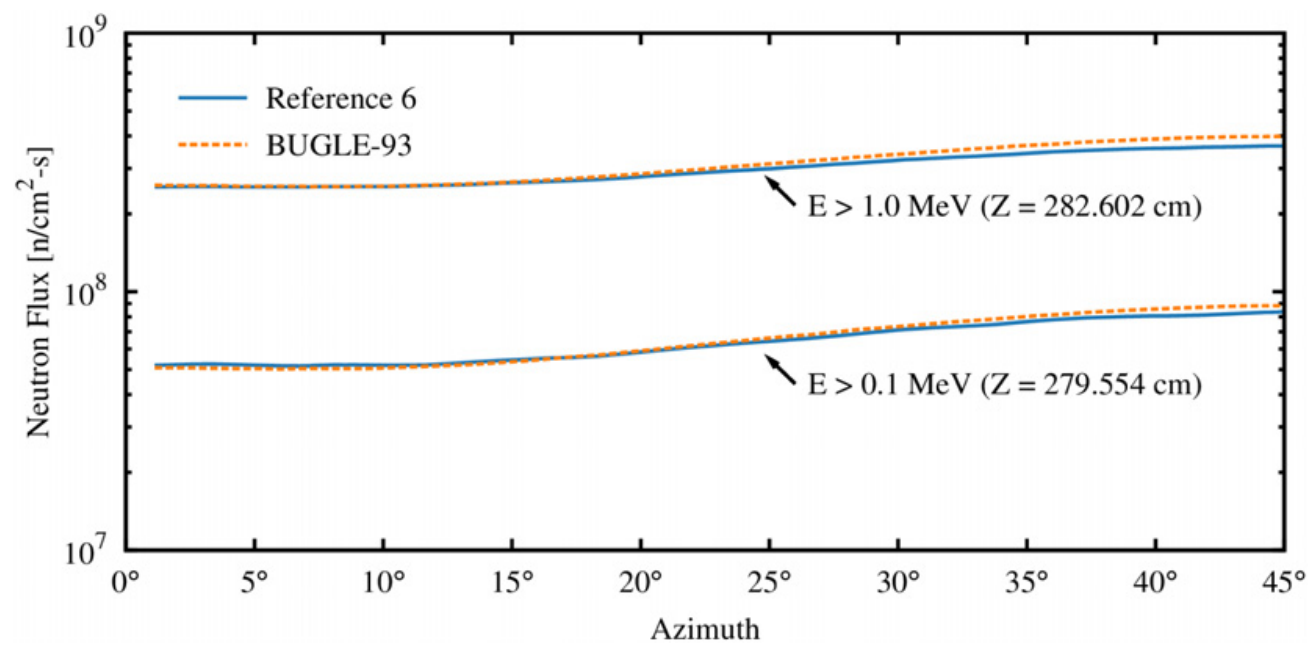

Figure 4. Comparison of Azimuthal Flux Traverses Within the Reactor Cavity (R=398.70 cm).

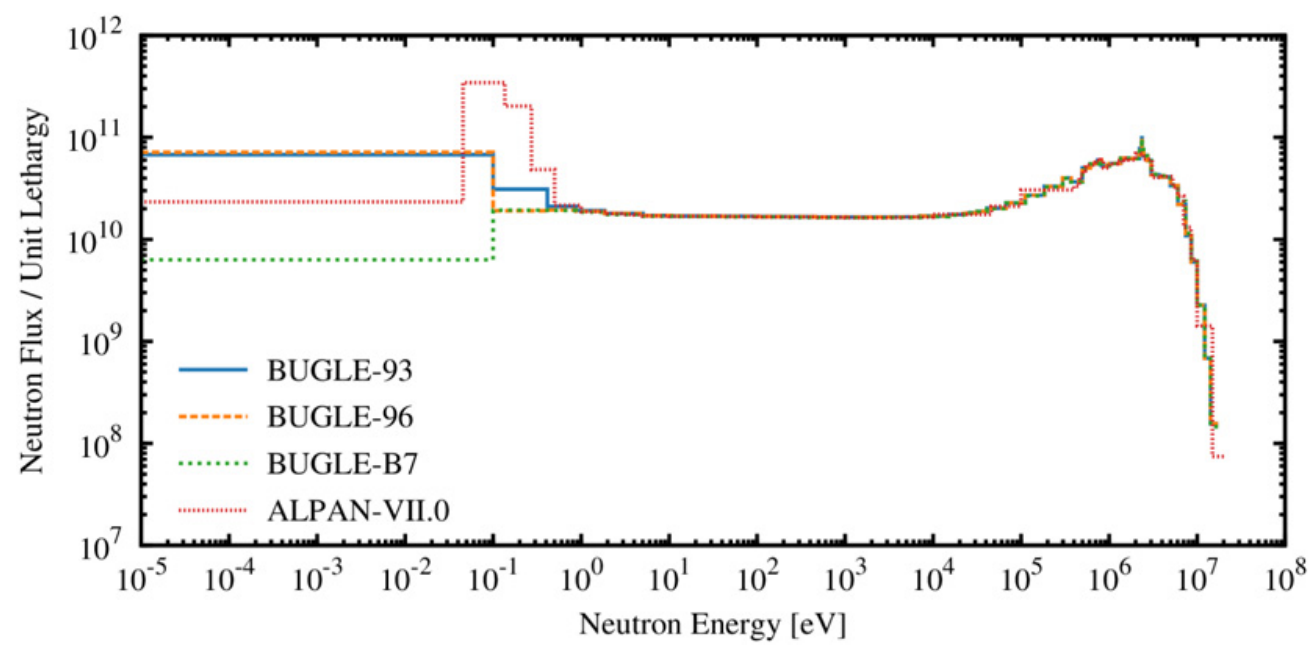

Figure 5. Downcomer Flux Spectrum for BUGLE-93, BUGLE-96, and BUGLE-B7.

(Downcomer, Pressure Vessel Capsule, and Cavity) are defined in Table 1. In addition, BUGLE-93 results were compared with Reference 6 at various positions in the pressure vessel for fast $(\mathrm{E}>1.0 \mathrm{MeV})$ flux results as well as two points in the reactor cavity for both $\mathrm{E}>1.0 \mathrm{MeV}$ and $\mathrm{E}>0.1 \mathrm{MeV}$ flux results as shown in Figs. 3 and 4, respectively.

The agreement between the spectra at the three locations shown in Fig. 2 and the flux comparisons shown in Figs. 3 and 4 is sufficient to conclude that the calculational model developed herein accurately represents the model used within the benchmark. With that, Figs. 5, 6, and 7 show comparisons of flux per unit lethargy as a function of energy for the three locations of interest between each of the three cross-section libraries analyzed. Note that there are differences in neutron fluxes calculated by the four libraries, as shown in Figs. 5, 6, and 7, particularly in the thermal energy range $(\mathrm{E}<5 \mathrm{eV})$. When BUGLE-93 was developed, upscattering in the thermal energy range was not considered; upscattering was introduced in BUGLE-96 as an improvement to BUGLE-93. While upscattering was considered 


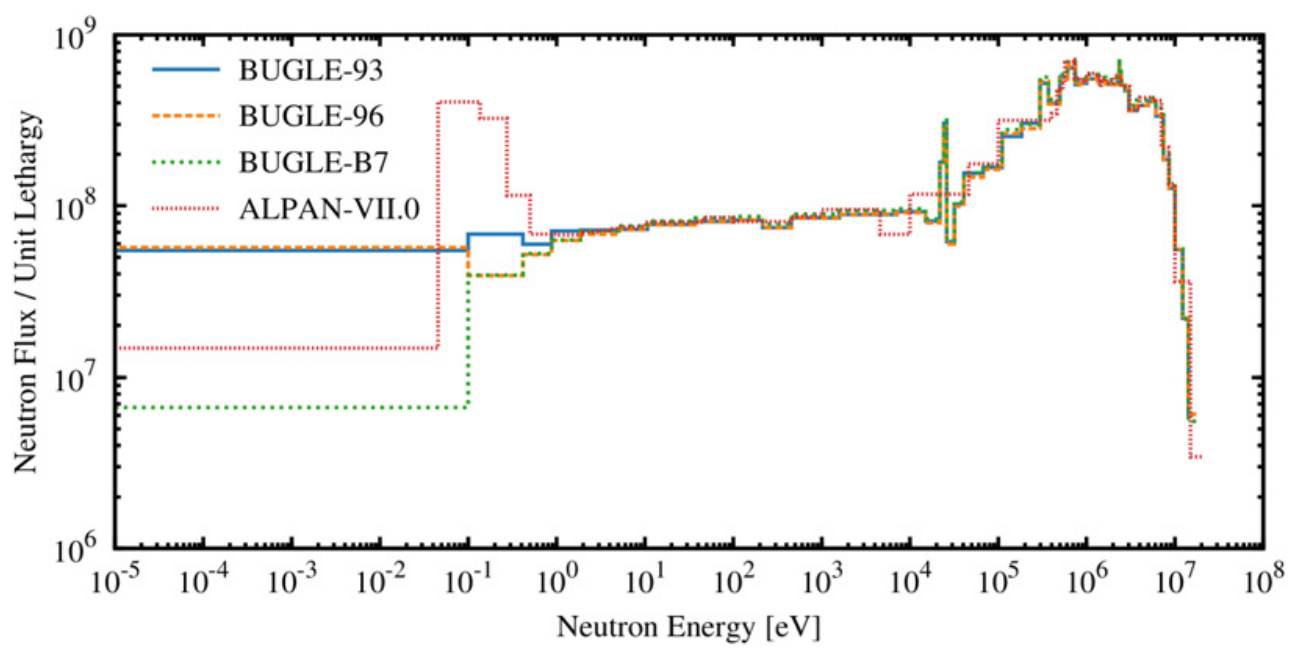

Figure 6. Pressure Vessel Capsule Flux Spectrum for BUGLE-93, BUGLE-96, and BUGLE-B7.

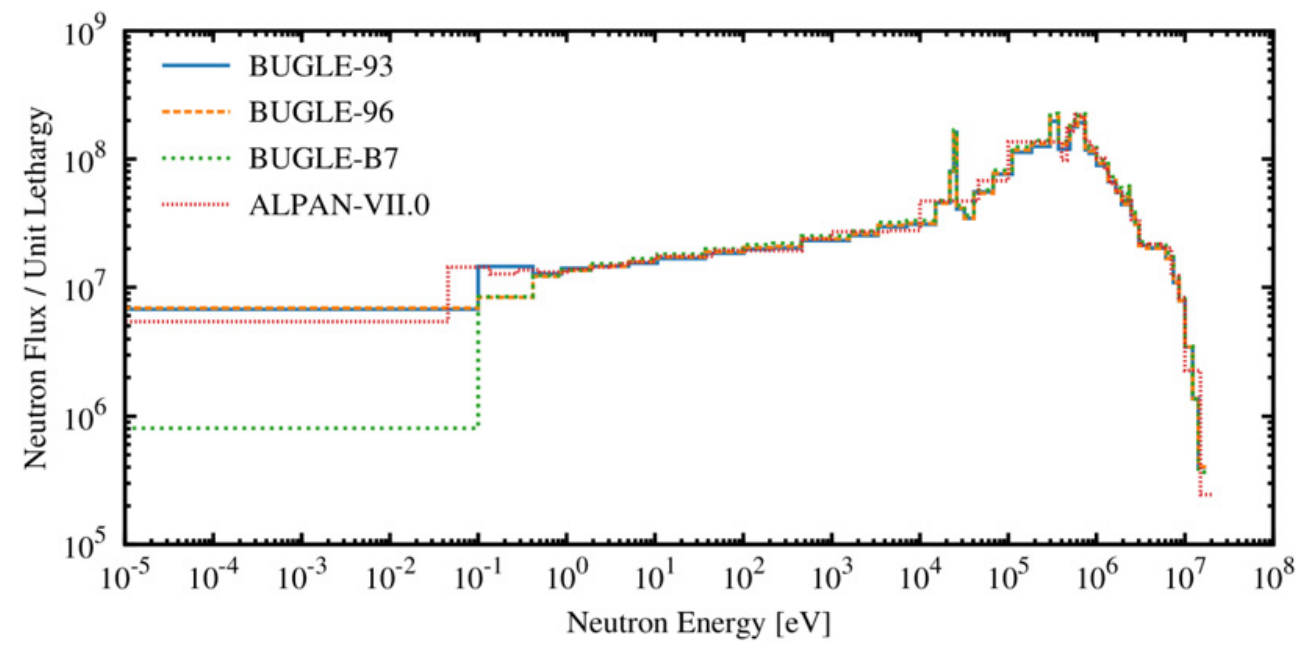

Figure 7. Reactor Cavity Flux Spectrum for BUGLE-93, BUGLE-96, and BUGLE-B7.

in the newer libraries, i.e., BUGLE-96, BUGLE-B7, and ALPAN-VII.0, the upscattering treatment used in BUGLE-96 and ALPAN-VII.0 differ, which is observed as differences in the thermal energy range in Figs. 5, 6, and 7. ALPAN-VII.0 uses the ANISN method of upscattering treatment. While the BUGLE-96 manual specifies that the ANISN method of upscattering treatment is used in BUGLE-96, investigation has shown that this is not the case. Regarding BUGLE-B7, a detailed investigation on the upscattering treatment will be performed, but according to comparisons between BUGLE-B7 and BUGLE-B7T, it is thought that BUGLE-B7 also does not incorporate the ANISN method of upscattering treatment. Table 2 gives neutron fluxes for $\mathrm{E}>1.0 \mathrm{MeV}$ and $\mathrm{E}>0.1 \mathrm{MeV}$ and comparisons with Reference 6.

It should be noted that in addition to the sheer scale of the geometry modeled and the large region of low-scattering (which can introduce various undesirable transport phenomena such as ray effects), 


\section{$15^{\text {th }}$ ISRD}

Table 2. Pressure Vessel Capsule Flux Magnitude and Relative Difference With Respect to Reference 6.

\begin{tabular}{|c|c|c|c|c|c|}
\hline Parameter & Reference 6 & BUGLE-93 & BUGLE-96 & BUGLE-B7 & ALPAN-VII.0 \\
\hline $\begin{array}{c}\text { Flux (n/cm }{ }^{2} \text {-s) } \\
\mathrm{E}>1.0 \mathrm{MeV}\end{array}$ & $9.671 \mathrm{E}+08$ & $9.832 \mathrm{E}+08$ & $9.827 \mathrm{E}+08$ & $1.048 \mathrm{E}+09$ & $1.031 \mathrm{E}+09$ \\
\hline Rel. Diff. (\%) & - & $2 \%$ & $2 \%$ & $8 \%$ & $7 \%$ \\
\hline $\begin{array}{c}\left.\text { Flux (n/cm }{ }^{2}-\mathrm{s}\right) \\
\text { E }>0.1 \mathrm{MeV}\end{array}$ & $1.808 \mathrm{E}+09$ & $1.903 \mathrm{E}+09$ & $1.897 \mathrm{E}+09$ & $2.018 \mathrm{E}+09$ & $1.965 \mathrm{E}+09$ \\
\hline Rel. Diff. (\%) & - & $5 \%$ & $5 \%$ & $12 \%$ & $9 \%$ \\
\hline
\end{tabular}

Table 3. Pressure Vessel Capsule Fast Reaction Rate Percent Relative Differences With Respect to Reference 6.

\begin{tabular}{|c|c|c|c|c|}
\hline Dosimetry Reaction & BUGLE-93 (\%) & BUGLE-96 (\%) & BUGLE-B7 (\%) & ALPAN-VII.0 (\%) \\
\hline${ }^{46} \mathrm{Ti}(\mathrm{n}, \mathrm{p})$ & $2 \%$ & $2 \%$ & $8 \%$ & $8 \%$ \\
\hline${ }^{54} \mathrm{Fe}(\mathrm{n}, \mathrm{p})$ & $1 \%$ & $1 \%$ & $8 \%$ & $7 \%$ \\
\hline${ }^{58} \mathrm{Ni}(\mathrm{n}, \mathrm{p})$ & $1 \%$ & $1 \%$ & $8 \%$ & $7 \%$ \\
\hline${ }^{63} \mathrm{Cu}(\mathrm{n}, \alpha)$ & $2 \%$ & $2 \%$ & $8 \%$ & $7 \%$ \\
\hline${ }^{237} \mathrm{~Np}(\mathrm{n}, \mathrm{f})$ & $2 \%$ & $2 \%$ & $8 \%$ & $7 \%$ \\
\hline${ }^{238} \mathrm{U}(\mathrm{n}, \mathrm{f})$ & $1 \%$ & $1 \%$ & $7 \%$ & $6 \%$ \\
\hline
\end{tabular}

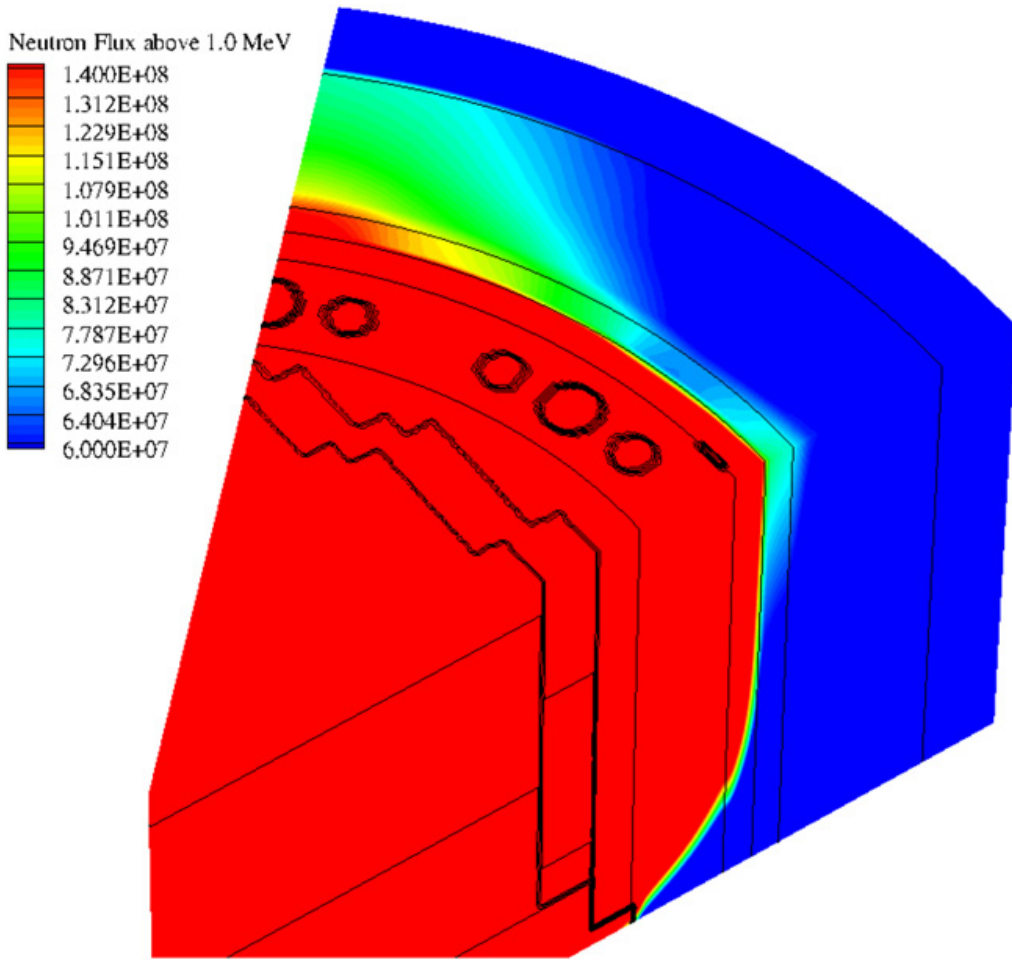

Figure 8. Fast $(\mathrm{E}>1.0 \mathrm{MeV})$ Neutron Flux Behavior at Reactor Cavity Reporting Elevation (using BUGLE-93).

the BWR cavity flux behavior can be difficult to resolve because of the perturbations caused by the jet pumps and risers in the downcomer region. Figure 8 shows a flux plot at the elevation of the cavity reporting position to demonstrate the variation in fast $(\mathrm{E}>1.0 \mathrm{MeV})$ neutron flux magnitude in the cavity (which would, in turn, lead to uneven ex-vessel activation and concrete heating).

Table 3 gives calculated dosimetry reaction rates and comparisons of results with Reference 6 for the pressure vessel capsule. The maximum relative difference considering all three library-calculated 
results is $8 \%$ (between BUGLE-B7/ALPAN-VII.0 and the benchmark that uses BUGLE-93). The 8\% difference represents the different evaluated nuclear data used between the libraries.

\section{Summary}

Comparisons between calculated flux and reaction rate results from RAPTOR-M3G using BUGLE93, BUGLE-96, and BUGLE-B7 for the U. S. NRC BWR benchmark verify the transport methodology of RAPTOR-M3G. Furthermore, the BUGLE cross-section libraries from different times and using different source nuclear data libraries investigated herein are found to be self-consistent. This selfconsistency further validates historical calculations based on the older cross-section libraries.

\section{References}

[1] G. Longoni, S. L. Anderson, World Scientific Publishing Co. Pte. Ltd., 722-732 (2009)

[2] D. T. Ingersoll, J. E. White, R. Q. Wright, H. T. Hunter, C. O. Slater, N. M. Greene, R. E. MacFarlane, R. W. Roussin, ORNL-6795 (1994)

[3] J. E. White, D. T. Ingersoll, R. Q. Wright, H. T. Hunter, C. O. Slater, N. M. Greene, R. E. MacFarlane, R. W. Roussin, ORNL-6795, NUREG/CR-6214, Revision 1 (1999)

[4] J. M. Risner, D. Wiarda, M. E. Dunn, T. M. Miller, D. E. Peplow, B. W. Patton, NUREG/CR-7045, ORNL/TM-2011/12 (2011)

[5] F. A. Alpan, Journal of ASTM International, 548-560 (2012)

[6] J. F. Carew, K. Hu, A. Aronson, A. Prince, G. Zamonsky, NUREG/CR-6115, BNL-NUREG$52395(2001)$

[7] V. McLane and Members of the Cross Section Evaluation Working Group, BNL-NCS-17541, (1996)

[8] M. B. Chadwick, P. Oblozinsky, M. Herman et al., Nuclear Data Sheets, 107, pp. 2931-3060, (2006)

[9] F. A. Alpan, A. Haghighat, Nuclear Science and Engineering, 149, No. 1, pp. 51-64 (2005)

[10] F. A. Alpan, J. A. Kulesza, 15 ${ }^{\text {th }}$ Int'l Symp. Reactor Dosimetry, EPJ Web of Conferences, 2014 